\title{
A MULTIDISCIPLINARY LANDSLIDE CASE STUDY: DEVREK LANDSLIDE
}

\author{
K. S. Gormus ${ }^{1}$, S. H. Kutoglu ${ }^{1}$, G. Gurbuz*1, O. F. Capar ${ }^{2}$, V. Akgul ${ }^{1}$ \\ ${ }^{1}$ Department of Geomatics Engineering, Bulent Ecevit University, 67100 Zonguldak, Turkey - sedargormus@ hotmail.com, \\ kutogluh@hotmail.com,gokhanngurbuz@gmail.com, akgulvo@gmail.com. \\ ${ }^{2}$ Department of Civil Engineering, Bulent Ecevit University, 67100 Zonguldak, Turkey - ocapar@yahoo.com
}

KEY WORDS: Landslide, Terrestrial Laser Scanning, Land-based SAR, Geotechnical

\begin{abstract}
:
Landslides are one of the leading causes of loss of life and property in the World. Landslides are the most profound ones within other mass movements. Especially in the Northern region of Turkey is severely threatened by landslides. Mass movements can be divided several main classes which are falls, slides, creeps, flows and complex movements. Landslides can occur due to a variety of reasons and most basic one of them is the angle of repose or slope of the hillside. If the angle is overly steep, gravity will pull the material downward, causing a mass movement. Many studies have been carried out in Turkey to monitor landslides, prevent and reduce landslides damage. These studies mostly focused on forecasting of landslides and damage determination after landslides. Activities required to be carried out in the field can be resulted with unwanted consequences for work safety while the landslide is still active. A landslide is triggered at Devrek, Zonguldak on July 16th, 2015 which affected an area of 40 hectares. For this reason, 88 buildings and a school are evacuated by authorities. To support emergency action plan while ongoing active landslide occurrence at Devrek, apart from the geotechnical approach, aerial photogrammetry, terrestrial laser scanning, land-based SAR methods are used. This study is a summary of studies carried out simultaneously with an active landslide at Devrek, Zonguldak on July 20th August 8th, 2015.
\end{abstract}

\section{INTRODUCTION}

Landslides are one of the natural disasters that take place due to several reasons such as underground water, rainfall, earthquakes, volcanic activities, mining activities, and superstructure studies. It happens in the form of mass movements that occur on earth, slides, creeps, flows, and complex movements (Tarchi et al., 2003). The main factor of the landslides is water and the mass is solidly displaced on a floor suitable for slipping. This kind of landslides frequently occur especially in the Black Sea region of Turkey, which has abundant rains, steep slopes and is rich in moisture.

The characteristics of steep slopes, rainfall, rocks and soils can play a role in the realization of the landslide (Dobrescu et al., 2011). The higher slope in the region causes to the higher risk of landslide realization. The masses can easily be displaced in areas where the slope is high. With the increase of rains or the melting of snow and ice, water leaks between the layers and makes easier the movement of the masses.

Landslides can cause very serious loss of life and property. It may ends up with the houses are collapsed and the roads of transport are closed. Therefore, superstructures due to the urbanization should be avoided in areas where landslide danger exists and possible movements in these areas should be observed. Early warning systems against possible landslide activities must be developed, and the emergency action plans and risk management systems must be realized to decrease damage during the landslide (Stähli et al., 2015; Manconi and Giordan, 2015; Rossi et al., 2012; Bogena et al., 2007). After the disaster, characteristic, size and damage of the landslide should be determined.

Observations of active landslides are accompanied by problems of work safety as well as the work done becomes difficult. It will be necessary to get near the object to be observed as the measuring distance of the instrument decreases. It should be selected a safe and stationary area while monitoring the targets. Observation of the points with totalstation provide the opportunity to learn about the data interpretation and disaster activity measured in a short period of time, even though it is difficult and dangerous to enter disaster area. And, it is accepted that repeated measurements performed with terrestrial laser scanners with effective point scanning in short distance measurements are also an appropriate method for determining detailed deformations (Barbella and Fiani, 2012). Aerial photogrammetry is another measurement technique with a high spatial resolution that can accurately determine disaster in a regional sense, but its high cost is a big disadvantage (Walstra et al., 2007). Ground based SAR techniques are also among the methods that can be used to determine regional disaster in the case of convenient land conditions (Tarchi et al., 2003).

In this study, landslide disaster which started on 16 July 2015 in Devrek / Zonguldak and continued with heavy mass movement for about 3 weeks has been discussed. On-site observations have been started on July 20, 2015 and continued with different measurement techniques during the movements. All the landslide area was tried to be observed with aerial photogrammetry and ground based SAR techniques as well as local observations with the totalstation, terrestrial laser scanner (Natural Disasters Research and Application Team, 2017). In view of the observations, the direction and daily speed estimations of displacement have been made.

\section{LANDSLIDE MONITORING}

\subsection{Local Measurements}

Firstly, safe working environment was created in the landslide area after reaching there. Ground points $(\mathrm{P} 1, \mathrm{P} 2, .$.$) were set up$ in the landslide heel zone in order to monitor whether the landslide activity continues or not. These points were monitored 
by totalstation with 30 minutes interval measurements for 5 days from an observation point not affected by landslide. Based on observations, direction and speed estimates of mass movements were made.

\begin{tabular}{|c|cccc|}
\hline \multirow{2}{*}{ Date } & \multicolumn{4}{|c|}{ Daily Displacements (m) } \\
& P1 & P2 & P3 & P4 \\
\hline $7 / 22 / 2015$ & & -0.739 & -1.210 & -1.306 \\
$7 / 23 / 2015$ & & -0.830 & -1.221 & -1.227 \\
$7 / 24 / 2015$ & & -0.756 & -1.044 & -1.044 \\
$7 / 27 / 2015$ & -0.516 & -0.684 & -0.792 & -0.804 \\
$7 / 28 / 2015$ & -0.451 & -0.566 & -0.643 & -0.710 \\
\hline
\end{tabular}

Table 1 Daily displacements

Based on the observations made at the points established in the ground, as shown in Table 1, the displacements of $130 \mathrm{~cm}$ per day at the defined speeds diminished in the following days. Depending on the speed and direction estimates, it is witnessed that a house in the area was destroyed.

The people, who are evicted from the houses with the danger of collapsing due to the landslide, are in an effort to overcome security measures and rescue their various things from their abandoned houses without considering the safety of their lifes. Observations made in such an environment gave a chance to notice that the landslide is still active and can cause severe damage.

\subsection{Terrestrial Laser Scanning}

At the point where active landslides remain, one of the other important issues is that some buildings can stay under risk in the vicinity of the landslide. With this approach, it has been possible to trace the structural deformations by using the terrestrial laser scanning method on some buildings within the possibilities. The most striking results among the studies performed with the Terrestrial Laser Scanning technique from $27^{\text {th }}$ July to $1^{\text {st }}$ August, were obtained at observations in Devrek Imam Hatip High School.

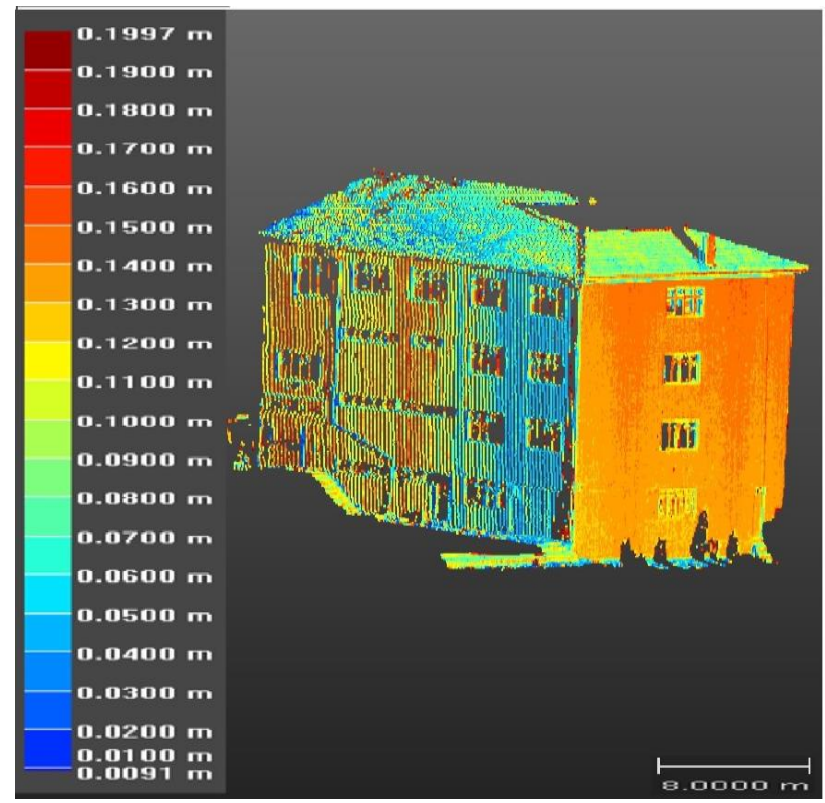

Figure 1. Terrestrial Laser Scanning Difference View, Devrek Imam Hatip High School
Figure 1 shows the difference image of this building on the $27 / 07 / 2015$, produced from two measurements conducted two hours period. According to these scanning results, deformations varying from $1 \mathrm{~cm}$ to $20 \mathrm{~cm}$ have been found on the building over a period of 2 hours. When the results posed a serious threat to the safety of the building, the danger was immediately conveyed to the relevant units. With safety measures taken around the building, the building collapses itself the next day.

\subsection{Aerial Photogrammetry}

In the landslide area in Devrek, on July 23, 2015, 17 aerial photographs were taken with Ultracam Eagle Digital Aerial Camera at $10 \mathrm{~cm}$ ground sampling interval with $80 \%$ forward and $60 \%$ side overlap rates. The 6 geodetic points selected and measured from the region was used as ground control points. Subsequently, a digital surface model with a resolution of $70 \mathrm{~cm}$ was produced by intensive mapping technique. The orthophotos and digital surface model produced from $45 \mathrm{~cm}$ resolution photos taken in 2011 belonging to the same region as well as the updated data for the analysis of the change in the region were obtained from the General Command of Mapping. Figure 2 shows the state of the landslide area in 2011, Figure 3 shows the state after the landslide on July 23, 2015.

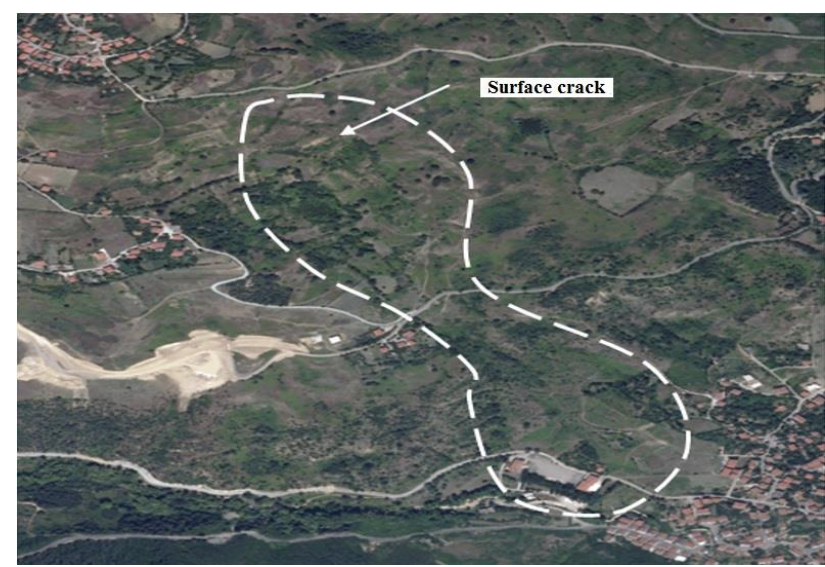

Figure 2. 2011 Stereo view of orthophoto image obtained from General Command of Mapping

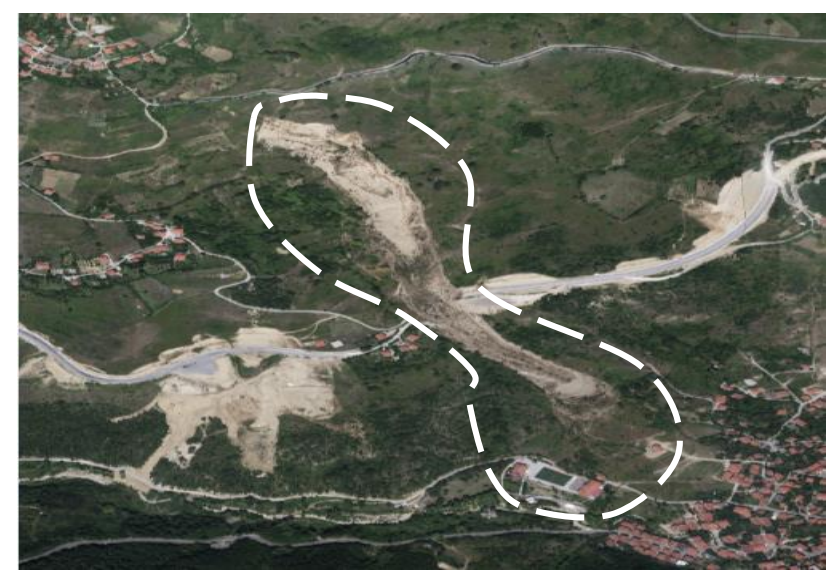

Figure 3. 2015 Stereo view of orthophoto image obtained from General Command of Mapping

The mass loss in the upper right corner of the motion boundary in Figure 3 is due to a planned operation caused by the road construction. The changes in the other regions are due to landslide. As it seen from Fig. 3, the landslide follows a path 
like "S" along a distance of about 1300 meters and changes direction 4 times.

\subsection{Ground Based SAR}

Ground based SAR application has been tried to observe the invisible movements in the places outside the field which is emptied due to the landslide. The ground based SAR device is a prototype and its characteristics are given in Table 2.

\begin{tabular}{|lc|}
\hline Center Frequency & $76.5 \mathrm{GHz}$ \\
\hline Wavelength & $3.92 \mathrm{~mm}$ \\
\hline Band Width & $450 \mathrm{MHz}$ \\
\hline Modulation Method & $\mathrm{FM}-\mathrm{CW}$ \\
\hline Antenna Power & $10 \mathrm{~mW}$ \\
\hline Range Resolution & $67 \mathrm{~cm}$ \\
\hline & 1.37 degree \\
Azimuth Resolution & $2.4 \mathrm{~m} \mathrm{@} 100 \mathrm{~m}$ \\
\hline Weight & $10 \mathrm{~kg}$ \\
\hline Unit Size & W32×D10×H16 cm \\
\hline Parabora Size & $19 \mathrm{~cm}$ \\
\hline
\end{tabular}

Table 2. Features of SAR equipment

After the device transition completed, ground based SAR observations started on 02/08/2015 and continued until 05/08/2015 (Figure 4).

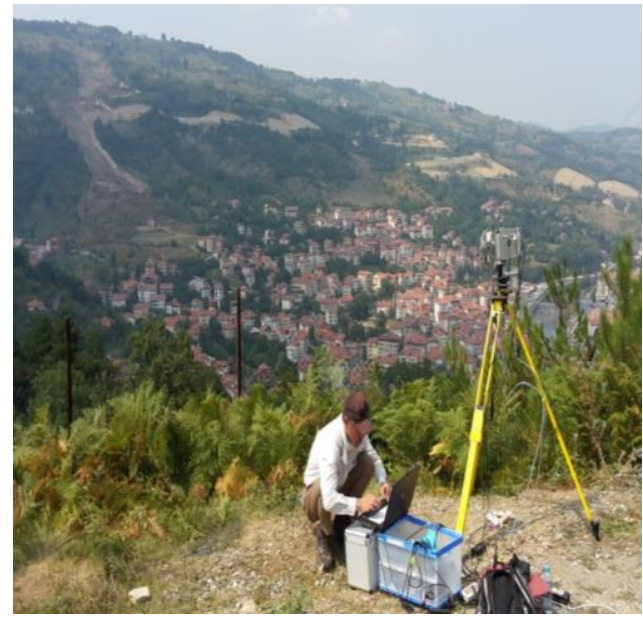

Figure 4. Ground based SAR observations

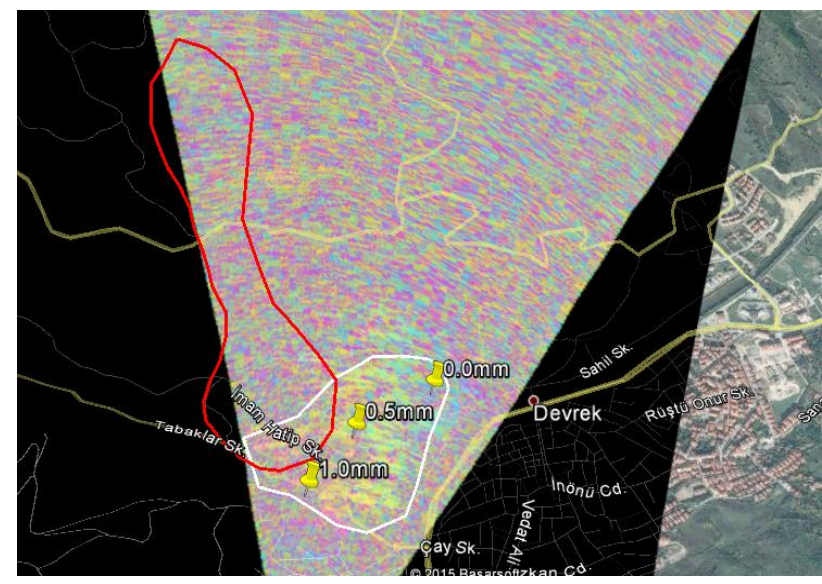

Figure 5. Analysis of ground based SAR observations
Figure 5 shows the phase interferogram obtained by SAR observations conducted on $03 / 08 / 2015$. According to the interferogram, the colorings pointing to the ground motion in the area surrounded by a white line surrounding a part of the landslide area defined by the red line but not the majority, are projected. This movement, which is on the order of 0.5 to $1 \mathrm{~mm}$ on an hourly basis, is around $1.2-2.4 \mathrm{~cm}$ on a daily basis.

The area in which the current landslide is located remains within the risky area defined by the risk map prepared in the past. Moreover, the area in which the motion is detected by the ground based SAR is within the bounds of the designated risky area in this map.

\subsection{Geotechnical Approach}

Çaycuma formation was observed in the landslide area. This formation contains weak and weathered sandstone, claystone alterations. According to previous geotechnical investigations, the total depth range of the soils layers overlying Çaycuma formation change between 1.0 and $21.35 \mathrm{~m}$ and the slopes of the land before the landslide fell between 10-30\%. From laboratory test results, the upper soil layers of Çaycuma formation were mostly classified as low plastic (CL), high plastic $(\mathrm{CH})$ clay, barely silty gravel (GM), clayey gravel (GC) soil layers. It was found that the ranges of water content, liquid limit, plastic limit and plasticity index for the soil layers are $10.8-27.9 \%, 31.9-55.1 \%, 18.8-31.7 \%$, and $12.2-28.1 \%$, respectively. Because of the high-plasticity clay soil layers, this formation frequently have caused regional rotational and translational landslides in the area.

Four individual landslides were recognized by examining deformation features. As seen in Figure 3. Approximately the landslide is about $1300 \mathrm{~m}$ long $(\mathrm{S}$ shape $)$ and ranges from 80 $140 \mathrm{~m}$ wide. Since the direction of landslip changed 4 times, it was very complex landslide. First, the depth of the landslip was determined as $15-20 \mathrm{~m}$ and the second plane was 5 meters deep. The third and the fourth the depth of the slip planes were 7-8 and 4 meters respectively.

The first landslide can be categorized as rotational landslide. Crown cracks is easily recognized and the surface of rupture is curved (spoon-shaped). The rest of movements might be termed as a translational landslide because they are shallower than the rotational one.

\section{CONCLUSION}

Although the area has been declared as a landslide area by General Directorate of Mineral Research and Explorations (MTA) in the past, it has been illegally constructed by the local people after a long period of inactivity. The place where the landslide begins to break is a place where heavy construction equipment passes because of road construction work.

As a result of the analysis performed on the deformation map produced by comparing the 2011-2015 orthophoto images, it was determined that the landslide route is approximately 1300 meters and the area is 38.9 hectares. Moreover, it has been determined that the disaster is not a single landslide, at least four successive landslides trigger each other. The depth of slip plane of these landslides is determined as 15-20 meters, 5 meters, 7-8 meters and 4 meters respectively from top to bottom. 
It was observed that the landslide area was located between two fault planes according to the active fault map of MTA and it was evaluated that the existence of these faults would play a trigger role in the landslide but it played an inhibiting role on the last point of the landslide.

Observations about 20 days after the beginning of the landslide showed that the rate of landslide was considerably smaller than the first days. Then, at the crisis table meeting, the following decisions:

Since the summer season will be over and the rainy season will be started, starting the load reduction and drainage studies starting from top of the landslide,

To provide flow again in the stream bed that is blocked due to landslides and to take precautions in the upper regions to avoid closure in possible new disasters,

The establishment of a ground motion monitoring system in the region due to small scale ground motion outside the landslide area detected by ground based SAR and the risk of landslide in the adjacent areas of the MTA's map

were taken.

It is cost effective but it is suggested to start identifying the nature of these mistakes to ensure that future plans are healthy in Devrek.

\section{ACKNOWLEDGEMENTS}

We would like to express our gratitude to the General Command of Mapping, which has been urgently returning to our calls during the active landslide process and to take aerial photographs of the region and to provide us the orthophotographs of the 2011 zone.

\section{REFERENCES}

Barbarella, M.; Fiani, M. (2012): Landslide monitoring using terrestrial laser scanner: Georeferencing and canopy filtering issues in a case study In: International Archives of the Photogrammetry, Remote Sensing and Spatial Information Sciences V, WG V/3, pp. 157-162.

https://doi.org/10.5194/isprsarchives-XXXIX-B5-157-2012

Bogena, H.R., Huisman, J.A., Oberdörster C. and Vereecken H., 2007. Evaluation of a low-cost soil water content sensor for wireless network applications. Journal of Hydrology, 344, 3242.

Dobrescu, C., Calarasu E. and Stoica, M., 2011. Landslides analysis using geological, geotechnical and geophysical data fromexperimental measurements in Prahova County. Urbanism, Arthitectură. Construcții, 2(4), pp. 55-62.

Manconi, A. and Giordan, D., 2015. Landslide early warning based on failure forecast models: the example of the Mt. de La Saxe rockslide, northern Italy. Nat. Hazards Earth Syst. Sci., 15, pp. 1639-1644.
Natural Disasters Research and Application Team of BEU, 2017. Devrek Landslide Application Report, BEU Geomatics Research Laboratory, Zonguldak, Turkey.

Stähli, M., Sättele, M., Huggel, C., McArdell, B.W., Lehmann, P., Van Herwijnen, A., Berne, A., Schleiss, M., Ferrari, A., Kos, A., Or, D. and Springman. S.M., 2015. Monitoring and prediction in early warning systems for rapid mass movements. Nat. Hazards Earth Syst. Sci., 905-917.

Tarchi, D., Casagli, N., Moretti, S., Leva, D. and Sieber, A.J., 2003. Monitoring landslide displacements by using groundbased synthetic aperture radar interferometry: Application to the Ruinon landslide in the Italian Alps. Journal of Geophysical Research: Solid Earth, 108: 2387, doi: 10.1029/2002JB002204

Walstra, J., Chandler, J.H., Dixon, N. and Dijkstra, T.A., 2007. Aerial Photography and Digital Photogrammetry for Landslide Monitoring. Geological Society London Special Publications, 283, pp. 53-63.

Rossi, M., Peruccacci, S., Brunetti, M.T., Marchesini, I., Luciani, S., Ardizzone, F., Balducci, V., Bianchi, C., Cardinali, M., Fiorucci, F., Mondini, A.C., Reichenbach, P., Salvati, P., Santangelo, M., Bartolini, D., Gariano, S.L., Palladino, M., Vessia, G., Viero, A., Antronico, L., Borselli, L., Deganutti, A.M., Iovine, G., Luino, F., Parise, M., Polemio, M., Guzzetti, F., Luciani, S. and Tonelli, G., 2012. SANF: a national warning system for rainfall-induced landslides in Italy. In: Landslides and Engineered Slopes: Protecting Society through Improved Understanding, Banff, Alberta, Canada, Vol. 2, edited by: Eberhardt, E., Froese, C., Turner, K., and Leroueil, S., pp. 1895-1899. 